\title{
Drag Reduction Using Additives in Smooth Circular Pipes Based on Experimental Approach
}

\author{
Allessandro Utomo, Achmad Riadi, Gunawan and Yanuar* \\ Mechanical Engineering, Department of Mechanical Engineering, Universitas Indonesia, \\ Depok 16424, West Java, Indonesia; allessandro.setyo@ui.ac.id (A.U.); achmadriadi@ui.ac.id (A.R.); \\ gunawan_kapal@eng.ui.ac.id (G.) \\ * Correspondence: yanuar@eng.ui.ac.id; Tel.: +62-818-897-518
}

Citation: Utomo, A.; Riadi, A.; Gunawan; Yanuar. Drag Reduction Using Additives in Smooth Circular Pipes Based on Experimental Approach. Processes 2021, 9, 1596 https://doi.org/10.3390/pr9091596

Academic Editors: Yoshimichi Hagiwara, Tomonori Waku and Satoshi Ogata

Received: 30 July 2021

Accepted: 31 August 2021

Published: 6 September 2021

Publisher's Note: MDPI stays neutral with regard to jurisdictional claims in published maps and institutional affiliations.

Copyright: (C) 2021 by the authors Licensee MDPI, Basel, Switzerland. This article is an open access article distributed under the terms and conditions of the Creative Commons Attribution (CC BY) license (https:// creativecommons.org/licenses/by/ $4.0 /)$.

\begin{abstract}
Reduction of fluid resistance using the rheological characteristics of a polymer-surfactant solvent is research that contains many aspects, such as the theory of the drag reduction process, historical journey, and ongoing current research development. Many studies have been conducted, but it is challenging to know all existing and new research threads. The present investigation was conducted using literature studies regarding drag reducing agents. This research will also discuss the characteristics of flowing fluids and their effects on the velocity profile with friction factor of flowing fluids in smooth circular straight pipe geometries based on experimental, theoretical approaches. It concludes with aspects of research conducted around reducing drag using drag reducing agents, ideas about innovations, structuring overlook in testing, and modification of the fluid flow state.
\end{abstract}

Keywords: fluid resistance; rheological characteristics; polymer-surfactant; drag reducing agents; fluid flow

\section{Introduction}

\subsection{History of Drag Reduction Additives}

Turbulence affects the movement of fluid on a wall. The movement of fluid occurs when there is increased turbulence resulting in a loss of adequate energy. Research seeks to reduce the energy loss due to friction generated by turbulent flow in walls. Studies were conducted [1-3] in which the discovery of the mechanism of reducing resistance or turbulent skin friction in moving fluids was made. The discovery involved the existence of different substances that can be used, namely polymer-surfactant agents, bio-biopolymers, and solids such as fibers mixed in the inhibitor reducing solution. However, the initial research did not focus on the solution formed but more on the turbulence mechanism in the fluid when a resistance-reducing solution is added. This research also applies to industries such as the petroleum industry, maritime industry, and shipping. The mechanism referred to in research [1-3] is that the addition of the solution affects the pressure required to decrease the turbulence that occurs in the working fluid in the paper mill when transporting the macerated paper.

Furthermore, Toms [4] took a closer look at polymer development by adding it to a Newtonian solution, thereby reducing wall shear stress. This effect is known as the Toms effect. The wall shear stress is reduced by $80 \%$ when the polymer solution is injected into a Newtonian turbulent flow resulting in a non-Newtonian solution. However, Toms has not fully explained this effect because he only clarifies the phenomenon that occurs. Oldroyd [5] describes the events that occurred very well. The external constraints occur on the pipe wall due to the presence of a laminar sub-layer produced by isotropic matter with a thickness proportional to the molecules' size in the moving fluid.

In the early days of research regarding drag reducing agents, despite the world being affected by a world war, there was a race to find the most effective way to transfer fluid. Weissenberg [6] changed the inner cylinder on a viscometer to produce steady shear, which 
was continued by Tom's research in 1958 [7], which used a poly(methyl) methacrylate. To produce 3\% polymer change, which showed a lower Weissenberg effect, the rheology of the temperature dependence of the polymer was reduced. Toms did this by adjusting the composition of the polymer mixed in a pure solvent using the Weissenberg method. The method was also used by [6], utilizing aluminum surfactant solvent to reduce the resistance flow of pipes for fuel.

At the same time, some studies [8,9] found that there are factors that influence low friction in non-Newtonian flow by using sodium carboxymethyl cellulose in water, which led to the development of biopolymers in this drag reducing agent study. Ten years after the development of this research, there was a development for industrial applications. Some researchers $[10,11]$ started using guar gum, a plant polysaccharide, as a drag reducing agent. A more in-depth investigation of the characteristics of surfactant polymers in turbulent flow in viscoelastic fluids was carried out $[9,12,13]$ with several properties. The reduction of turbulence is strongly influenced by the ratio of elasticity to the viscous force generated by the polymer. In addition to the military industry, the studies of [14,15] were the first to announce that the best polymer used as a drag reducing agent is poly (ethylene oxide). However, several things must be highlighted by further research [9]. References [16,17] examined the characteristics of the drag reducing agent from the aspect of pressure gradient and flow rate resulting from the turbulent flow of different polymers. This is only an initial aspect of the drag reducing agents that require attention. The quantitative theoretical aspects were finally clarified [18], namely polymer molecular weight, polymer concentration, and increased flow rate, increasing the drag reduction effect.

Notably, research on drag reducing agents has been discussed by several sources. A summary of the progress of these studies can be seen in Table 1. However, several reviews of drag reducing additives do not adequately specify the developments in the last decade. This study aims to develop and examine further developments and possible innovations that can be implemented in the next few years regarding drag reducing additives. The improvements can occur by innovating the solvent's chemical composition or the percentage of the solution. In addition, we examine the mechanism for reducing the resistance that occurs, which is useful for supporting the reduction of barriers, and suggestions for industries that can implement inventions and innovations in the world of chemical and mechanical engineering. This paper aims for completeness and specificity in its review. The definition of one additive with another is a significant factor because many reviews are still wrong in defining these additives. Then, we examine experimental research on smooth circular pipes; some studies have been excluded as they explore other factors such as duct or bend pipes, sometimes using simulations. These studies are nonetheless mentioned in Table 1. Finally, this study focuses on drag reduction caused by wall shear stress based on the difference in pressure gradient in the pipe. We address the final drag reduction result as the main concern is the final effect of the additives.

Table 1. Different review papers covering drag reducing additives.

\begin{tabular}{cc}
\hline Reference & Additive Drag Reduction Techniques \\
\hline Lumley [19] & Polymer and solvent additions \\
Patterson et al. [20] & Polymer solutions, soap solutions, solid particle suspensions, \\
straight pipeline \\
Hoyt [21] \\
Virk [22] & Polymer additive, rotating disk, straight pipeline, flat plate \\
Phite and Hemmings [23] & Polymer additions, straight pipeline \\
Shenoy [24] & Polymer additions, straight pipeline \\
Berman [25] & Polymer additive, solid suspensions solutions, biological \\
Hoyt [26] & additives, surfactant solutions, micellar system, polymeric system \\
& Polymer and solvent additions, straight pipeline \\
\end{tabular}


Table 1. Cont.

\begin{tabular}{|c|c|}
\hline Reference & Additive Drag Reduction Techniques \\
\hline Zakin et al. [27] & $\begin{array}{l}\text { Anionic soap solution, non-ionic solutions, zwitterionic surfactant } \\
\text { solution, cationic surfactant solution, straight pipeline }\end{array}$ \\
\hline Nadolink and Haigh [28] & $\begin{array}{l}\text { Bibliography of polymer additions, pipes/tubes, ducts, channels, } \\
\text { flat plates, asymmetrical, axisymmetric bodies }\end{array}$ \\
\hline Manfield et al. [29] & Surfactant additions, straight pipeline \\
\hline Graham [30] & $\begin{array}{c}\text { Dilute polymer solutions, FENE spring model, spatial } \\
\text { discretization }\end{array}$ \\
\hline White and Mungal [31] & Polymer solutions, straight pipeline, channels \\
\hline Al Sharkhi et al. [32] & Polymer injection, straight pipeline \\
\hline Wang et al. [33] & $\begin{array}{c}\text { Fiber suspensions, polymer solutions, surfactant solutions, } \\
\text { straight pipeline }\end{array}$ \\
\hline Abdulbari et al. [34] & Bio-polymer solutions, polymer injection \\
\hline Nesyn et al. [35] & $\begin{array}{c}\text { Polymer injection, rotating disk, slurry polymerization, } \\
\text { surfactants solutions }\end{array}$ \\
\hline Xi [36] & FENE-P, Oldroyd-B, Giesekus models, polymer solutions \\
\hline Soares [37] & Polymer solutions \\
\hline Ayegba et al. [38] & $\begin{array}{c}\text { Polymer solutions, curved pipes, coiled pipes, ionic surfactants, } \\
\text { non-ionic surfactants }\end{array}$ \\
\hline Broniarz-Press et al. [39] & $\begin{array}{l}\text { Drag reduction and heat transfer in turbulent flow, straight tubes, } \\
\text { falling films, coils, polymer-surfactant drag reduction }\end{array}$ \\
\hline Boffetta et al. [40] & $\begin{array}{c}\text { Dilute polymer solutions, viscoelastic fluid model, numerical } \\
\text { analysis Kolmogorov flow }\end{array}$ \\
\hline
\end{tabular}

Several contributions are made in this manuscript: turbulence skin friction, which is the main reason drag-reducing agents research is conducted, will be explained; we also highlight several aspects of drag-reducing additive research, including variables, straight piping configurations, fluid characteristics that flow, type of fluids, and chemical and mechanical degradation. Different polymers, surfactants, and suspensions will be examined in terms of advantages and disadvantages. Lastly, we distinguish and discuss experimental approaches by debating the effectiveness of each approach, optimization, and suggestions for research that can be developed in the coming years.

\subsection{Drag Reduction Additives Properties}

The definition of drag reduction has been widely discussed in various manuscripts, research, and reviews. Drag reduction is a process that causes a decrease in frictional force when the fluid flow increases. The process is caused by an additive that reduces the shear stress in the fluid flow by utilizing a composition of the additive mixture and the moving fluid with a lower concentration of additives. As discussed [41], using the solution to reduce the resistance to the fluid flow moving in a turbulent position can be carried out by using xanthan gum in the form of polysaccharides to produce a drag reducer solution. However, the drag reduction process has been studied [42] to estimate the drag generated by a surface coated with lubricant. Of course, the effect is the interaction between the surface of the compound used and the moving fluid layer, which causes the shear surface to change, such that a bearing is formed on the surface structure and the shear stress decreases.

From these effects, the additives used can be distinguished based on their physical and chemical characteristics. Physical characteristics can be defined based on the drag reduction effect that can be achieved. Using Poiseuille's law equation, these effects can be summarized for pipe flow with laminar type with Equation (1). The manuscript [22] has become a clear benchmark in research around polymer-surfactant drag reduction.

$$
f^{-1 / 2}=\text { Re. } f^{1 / 2} / 16
$$


Furthermore, the effect of pipe flow with turbulent flow type can be analyzed using Blasius law for turbulent Newtonian flow [22]. However, turbulent flow can be considered as two relationships between the flowing fluid and the friction factor conditions. When the flow does not experience a reduction in drag, the friction factor condition is the same as the flowing additive. Otherwise, if there is a reduction in resistance, the friction factor depends entirely on the polymer-surfactant $\left(W^{*}\right)$ parameter. The flow without drag reduction can be calculated with Equation (2) and the flow with drag reduction asymptote $\left(f^{1 / 2}\right)$ can be calculated with Equation (3). Therefore, Equation (4) $[43,44]$ can be categorized as the maximum limit for reducing the resistance caused by the polymer-surfactant used.

$$
\begin{gathered}
f^{-1 / 2}=4 \log _{10}\left(\text { Re. } f^{1 / 2}\right)-0.4 \\
f^{-1 / 2}=(4+\delta) \log _{10}\left(\operatorname{Re} . f^{1 / 2}\right)-0.4-\delta \log _{10} \sqrt{2} d W^{*} \\
f^{-1 / 2}=19 \log _{10}\left(\text { Re. } f^{1 / 2}\right)-32.4
\end{gathered}
$$

The second parameter is the chemical characteristics of the polymer-surfactant. One study [45] distinguished between the types of soap used. Therefore, it can be concluded that this can only be distinguished using two differences. The difference is the morphology possessed by the compound. The morphology is compounded with micellar type and polymeric type, which were discussed in other studies [46].

The difference in these types can be seen in their chemical structure. The micellar structure is supported by ionic or molecular components with low concentrations in the fluid system. In comparison, the polymeric type is composed of interconnected macromolecules as isolated coils. The effect on drag reduction can be seen based on the shape of the component ions and the macromolecular structure of each type. The micellar type has been demonstrated in studies [47], where the shape of the micellar solution affects the inhibition reducing ability supported by high solution concentrations [48]. There are studies that provide specific differences between micellar shapes (spherical [45], rod [49], cylindrical [49]) and their drag reduction effect [45,49], proving that micellar variations can cause drag reduction effects [27] for surfactants. However, molecular sizes of $50 \mathrm{~nm}$ to $100 \mathrm{~nm}$ have a better drag reduction effect than variations below that size [50].

In contrast to the polymer type, as an important parameter, it has been demonstrated that the more extended a polymer arrangement is, the more significant the reduction in resistance [51]. The study also supports the molecular changes during the experiment, where it was found that the drag reduction effect decreased with the degradation of molecular weight because of chemical mixing. Thus, the influence of molecular weight is one of the considerations. In this case, the greater the molecular weight, the greater the reduction of shear stress on the fluid surface. This effect is also affected by the type of molecule, where the micellar type of molecule will have a more significant effect than the polymer type molecule.

\subsection{Drag Reducing Agents \\ 1.3.1. Polymer}

A polymer is a substance of molecular structure that consists of similar units of macromolecule that bonded together forming a chain of repeated units. Polymers are divided into two types, namely synthetic polymers and polymers formed from natural materials. The difference between synthetic polymers and natural polymers is their degradability. Synthetic polymers tend to be difficult to degrade, causing environmental problems. However, polymers have become a good benchmark in drag reducer research using additives of the two types. The research started in [4], which is useful for aiding in the transition of oil in the pipeline. Synthetic polymers have been widely discussed in research [24], examples of which include polyethylene oxide [52-56], polyisobutylene [57-61], poly (iso-decyl methacrylate) [62,63], polymethyl methacrylate $[57,64]$, polystyrene $[65,66]$, and others. Based on their effect on the environment, natural bio-degradable polymers have emerged, 
such as guar gum $[67,68]$, xanthan gum $[69,70]$, aloe vera, okra, locust bean, and others [34]. The efficiency of a polymer in causing a drag reduction is based on the molecular weight of the polymer; the higher the molecular weight, the more effective a polymer will be in producing a drag-reducing effect. This is because the polymer chain structure is getting longer and is supported by a low concentration so that it does not affect the chemical composition of the moving fluid. The molecular weight limit in question is above $10^{6}$ in order to become effective and more economical in use. The effect also supports the drag reduction process in that the polymer reduces the turbulence of the moving stream [71].

\subsubsection{Solid-Particle Suspensions}

Reduction of resistance using solid-particle suspensions is carried out by introducing solid particles to the moving stream with two different types of suspension [72], namely granulation and fiber. The difference between granular and fiber suspension is their size and components. Granular almost resembles a particle with a sphere shape, while fiber is a component formed from more than one material. Based on the given effect, the advantage of other drag reduction methods is that suspensions used in moving fluids can be separated easily due to their larger size. Furthermore, the suspension does not change the moving fluid components, which is supported by research on the degradation of solid-suspension particles [73]. This convenience is certainly an important consideration in its application to industrial-scale use in the maritime industry [74]. Examples of solid suspensions are sand $[75,76]$, charcoal $[77,78]$, wood pulp [79,80], nylon [81,82], asbestos $[83,84]$, and other suspensions [24].

\subsubsection{Surfactant Solutions}

Surfactant is a term used when a molecule or an uncategorized composition affects its environment [24]. Surfactants are basically divided into two broad categories, namely ionic and non-ionic. The difference between ionic and non-ionic is the ionic content possessed by a surfactant. If the surfactant is ionic, then there is a charge content and the opposite applies for non-ionic surfactants. Ionic surfactants can be further categorized into anionic, cationic, and zwitterionic [33] surfactants. Anionic surfactants were first researched by Savins from 1967 to 1969 [48,85,86] with the introduction of anionic surfactants used in aqueous solution systems.

Their invention [86] suggested a reduction in inhibition of $30 \%$ by adding a sodium oleate solution. An electrolyte is added to increase the reduction in resistance [87] to $81 \%$ to increase the impact. The consequence is closely related to the shear stress and the composition of the anionic surfactant used. The greater the anionic surfactant solution in the system, the less gradual the barrier effect will be. Hence, the unique composition introduced by Savins's use of this type of surfactant is unlike polymers, where 2000 to $2500 \mathrm{ppm}$ is an appropriate concentration for the system. The surfactant does not degrade at this concentration. It shows a steady reduction in resistance of $77 \%$ to $78 \%$ for $88 \mathrm{~h}$ of circulation in a centrifugal pump without any reduction in soap concentration. In addition to low concentrations, another advantage that arises is its effect on temperature. Efficiency will increase as the temperature of the system decreases. The advantages make it suitable for systems that work at low temperatures.

However, the disadvantage of using an aqueous system is that the solution will degrade when it encounters calcium and other ions, causing a chemical imbalance. The non-aqueous system of anionic surfactants differs in viscosity because anionic surfactants are added to a substance with low water content. Early in Myles's research in 1949, this was applied to fire-throwing weapons during World War II by combining napalm with soap and aluminum solutions to be sprayed more efficiently. In contrast to the aqueous system, the new non-aqueous impacts [88] show that drag reduction increases and is most efficient when the temperature is $15^{\circ} \mathrm{C}$. The presence of water also affects the solution, which progressively degrades over time [89,90]. Reference [90] emphasized that the degradation effect also depends on the hydrogen component and its interaction with surfactants. 
On the other hand, cationic surfactants were examined in [91], which distinguishes between various cationic surfactants. The discussed cationic surfactants were CTAB (cetyltrimethylammonium bromide), CTAC (cetyltrimethylammonium chloride), and Arquad S-50 (oleytrimethylammonium chloride). Nash studies [92,93] investigated CTAB, which resulted in a gel with high viscosity-elasticity. In contrast to other cationic surfactants, especially CTAB, it is affected by flow velocity. The drag reduction effect of CTAB is not significant when the flow is turbulent. The turbulence is, of course, observed based on increasing concentration [94]. Temperature also affects the system; reference [94] observed that shear stress degrades by $0.2 \%$ when the surfactant concentration reaches $0.05 \%$ with $35^{\circ} \mathrm{C}$. In contrast, compared to aqueous systems, cationic surfactants are not easily degraded when in contact with calcium and other ions. However, adding a temperature above $48{ }^{\circ} \mathrm{C}$ will reduce the drag reduction effect [95]. Regarding the Arquad S-50, the flow velocity is inversely proportional to CTAC and CTAB [91]. The friction factor decreases as the fluid velocity increases at a temperature of $18^{\circ} \mathrm{C}$. Cationic surfactants are useful when at an optimum temperature [91].

In addition, a study was carried out examining the drag reduction effects of a CTAC solution [96]. The maximum drag reduction obtained in this solution is $70 \%$, with experimental specifications discussed in other studies [97]. However, the pipe used in the study $[97,98]$ had high turbulence, so an Eddy rule had to be used to perform shifts resistance on fluid motion. Eddy's calculation appears when the pipe is no longer running, so it becomes another discussion. Nonetheless, CTAC is another option compared to CTAB in carrying out drag reduction.

The emergence of zwitterionic surfactants is the answer to of the ability of cationic surfactants to be less biodegradable. Some studies on zwitterionic surfactants use them in their pure form, without combining them with other surfactants or other ions. Research is usually carried out by combining zwitterionic surfactants with anionic surfactants. The study of zwitterionic surfactants [99] with a higher molar level than the aqueous fluid system effectively showed a drag reduction effect. Research [99] is supported by statements and findings by previous studies [100], with $20 \%$ zwitterionic content being the most optimum composition in producing drag reduction effects. Its effect on temperature has also been studied [101]. The optimum conditions for using this surfactant are $60{ }^{\circ} \mathrm{C}$ for $\mathrm{C}-16$ and $100{ }^{\circ} \mathrm{C}$ for $\mathrm{C}-18$ [100].

Finally, the study of non-ionic surfactants began with Zakin and Chiang [102], who examined non-ionic surfactants based on the concentration and type of electrolyte, surfactant concentration, and its mechanical effect as a drag reduction agent. Some findings that can be underlined from this research are that non-ionic surfactants certainly have no charge, meaning that the electrolyte they have is in a low composition. Second, the temperature affects the micelles owned by the surfactants. Micelles will swell and eventually split from the surfactant structure. The effect of temperature also gives two different types of conditions where the concentration is low and high when the drag reduction effect occurs. Low concentrations will have an effect when the flow is turbulent. Research on non-ionic surfactants with cationic surfactants can be distinguished in the study [103], where zwitterionic CAPB (Cocamidopropyl betaine) showed a higher drag reduction of $65 \%$ than cationic surfactant in turbulent flow with a composition of $0.12 \%$ DEA in the combined CAPB-DEA. It also adds a perspective of the effectiveness against cationic surfactants, which are insignificant in a turbulent flow.

On the other hand, the high concentration is in the transitional flow between turbulence. Among other surfactants, non-ionic surfactants are very stable mechanically and chemically. Where there is no degradation when it meets other ions, water, or seawater, this is supported by research [104] which showed that even with the application of introducing nanoparticles to the flow, the drag reduction effect did not produce a significant effect. Thus, according to Shenoy [105], a surfactant can even survive in high-temperature systems. 


\subsection{Drag Reduction}

As discussed at the beginning of the sub-section, drag reduction is a process to reduce the pressure lost due to fluid flow or the flow system owned by a pipe or even a flat plate. After the above discussion of drag reducing additives, the discussion now shifts to a mathematical perspective on the effects of reducing drag. Historically Toms [4] was the first to define reducing barriers to the use of additives to provide this effect. The investigation is carried out on the standpipe, therefore the determination of resistance reduction is based on the geometry of the pipe which will change along with the modification of the flowing pipe. This will be discussed in the next section. However, an illustration of the mathematical equation for the percentage of drag reduction can be seen in Equation (5) [38].

$$
\% D R=\frac{\left(\frac{d p}{d l}\right)_{S}-\left(\frac{d p}{d l}\right)_{D R A}}{\left(\frac{d p}{d l}\right)_{S}} \times 100 \%
$$

It can be simplified as follows (Equation (6)), where $f_{s}$ is the friction factor before the application of resistance reduction using additives $\left(f_{D R A}\right)$.

$$
\% D R=\frac{f_{s}-f_{D R A}}{f_{s}} \times 100 \%
$$

Friction factor $(f)$ is influenced by wall shear stress $\left(\tau_{w}\right)$, which is the product of the diameter of the pipe used and the resulting pressure difference is divided by 4 times the length of the pipe under study.

$$
f=\frac{\tau_{w}}{\left(0.5 \rho U^{2}\right)}, \tau_{w}=\frac{d . \Delta p}{4 l}
$$

However, because the pipe used by Toms is a straight pipe, it is necessary to define a mathematical equation for the diameter of the pipe, the geometry of the pipe, and the indentation of the pipe used in the experiment [106]. This will be discussed in the next section. Nonetheless, the above equation is one approach to research on drag reduction using additives.

\section{Straight Smooth Circular Pipes-Drag Reduction Additives}

\subsection{Experimental Setup}

In this section, the paper will discuss the application of lubricants using surfactant polymers based on experiments. This section will discuss the application of three divisions, namely straight smooth circular pipes, straight rough circular pipes, and wall ducts that have been widely carried out in research on drag reduction. In conducting a study between one type of pipe and the type of polymer-surfactant used, three essential things must be considered. The first is the concentration effect of the polymer or surfactant used. Then, the friction factor resulting from the experiment must be considered. Finally, the shape of the pipe so that the drag reduction effect can be generated must be discussed. The drawback of several reviews regarding the drag reduction effect using polymer-surfactant is recognizing the proper benchmark for experiments on polymer-surfactant drag reduction [25-29].

In a smooth, straight, circular pipe, experiments can be seen in research [107]. This manuscript has discussed a benchmark in researching neutral perpendicular pipes. Some things that need to be considered are the only temperature, the moving fluid flow velocity, the diameter, the velocity profile, and the friction factor. The following is a schematic of the experiments carried out, provided in Figure 1 as a tool setup for calculating the flow velocity. 


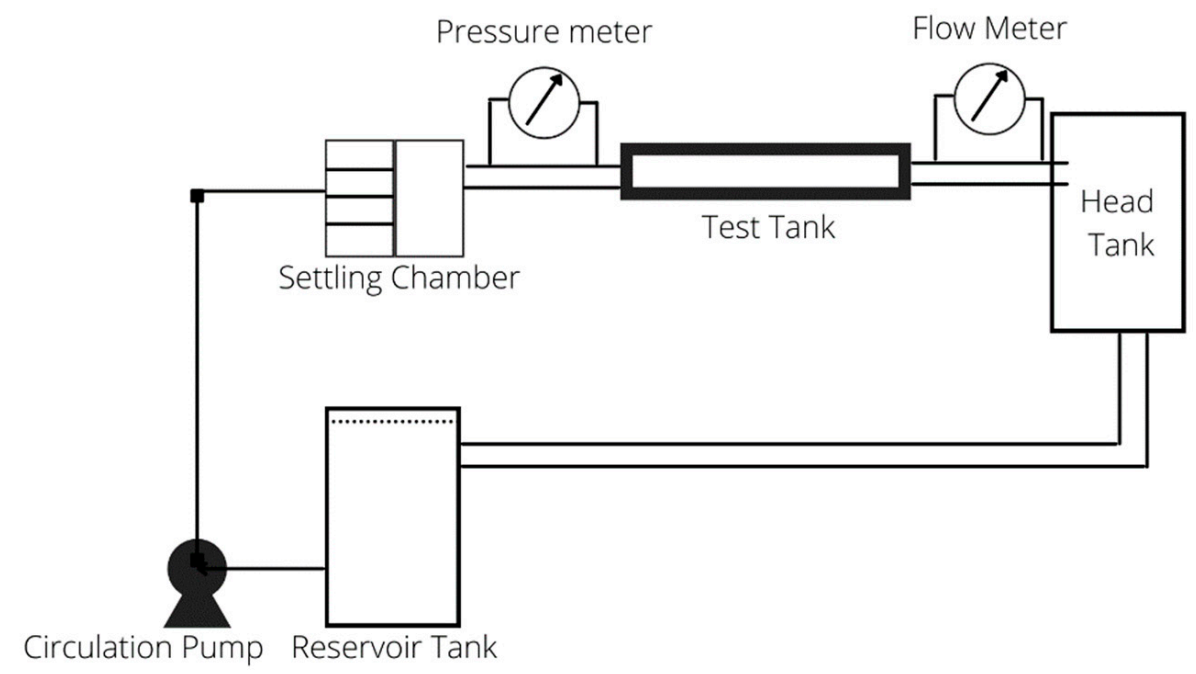

Figure 1. Schematic of the experiment on drag reduction using additives.

For velocity profile, the tool used is LDV. LDV applies because the uncertainty is lower than PIV. Based on [108], LDV has a level of uncertainty of $0.2 \%$, whereas PIV [109] has a level of uncertainty of $0.22 \%$; this is due to the resulting image where the laser influences the deflection from a glass pipe, which is the reason for using a glass pipe of $1.000292 \mathrm{~mm}$. In contrast, PIV is limited by the frame rate that can be generated [110]. Furthermore, the discussion is the calculation or analysis of the resulting physics. The friction factor in question is based on Equation (7).

$$
u^{+}=\frac{1}{k} \ln y^{+}+B
$$

In Equation (8), the calculation of the velocity profile in question can be seen. The equation is for the mean velocity profile where $u^{+}$is the average velocity. At the same time, $y^{+}$is the normal position from the wall to the fluid layer, while $k$ is the Kármán constant and $B$ is the additive constant used. $B$ in the future will be different depending on the additives used during the experiment. Figure 2 shows the results if water is used as a benchmark and the experiment does not use additives [108,111-113].

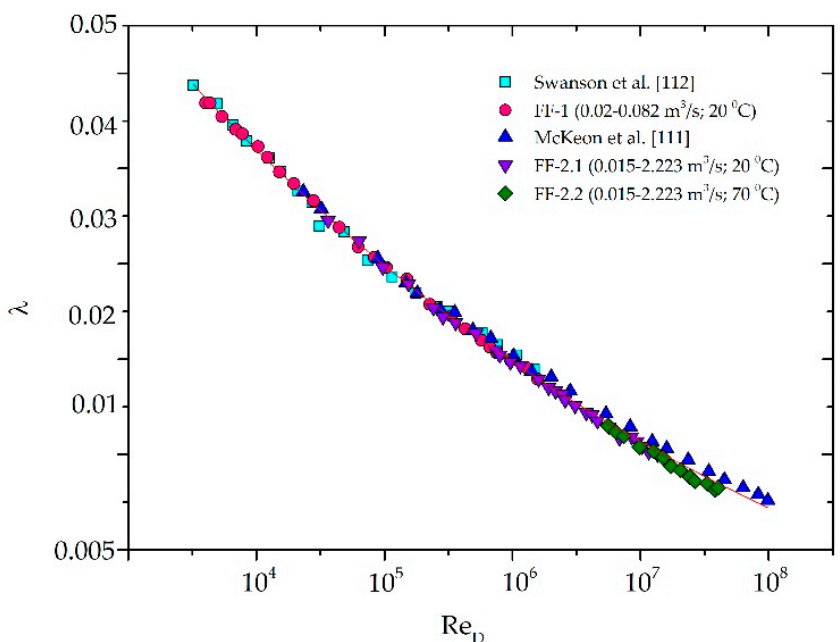

(a)

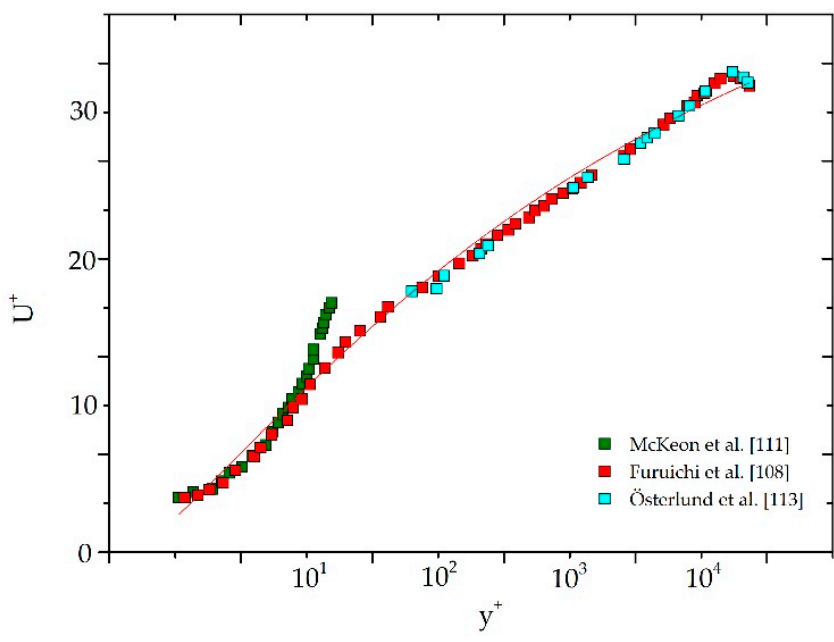

(b)

Figure 2. (a) Comparison between Reynold number $\left(7.1 \times 10^{3}>\operatorname{Re}_{\mathrm{D}}>1.8 \times 10^{7}\right)$ and the resulting friction factor $(\lambda)=(f)$ at different temperatures. (b) Velocity profile formed in the inner layer. 


\subsection{Polymer Drag Reduction}

The next aspect to discuss is the use of polymers and surfactants in the above pipe conditions. For polymers, Virk conducted pioneering, and now standard, research on straight, smooth, circular pipes, using polymers as additives [114]. The types of polymer species examined by Virk were PAM (polyacrylamide) and PEO (polyelectrolytic). The PAM type used in the Virk study were E198 and that for PEO was W205. These two types were used to show the effect of the polymer concentration on the resulting friction factor. The discussion of Equations (1)-(4) regarding the friction factor can be seen in Figure 3 based on other research [114].

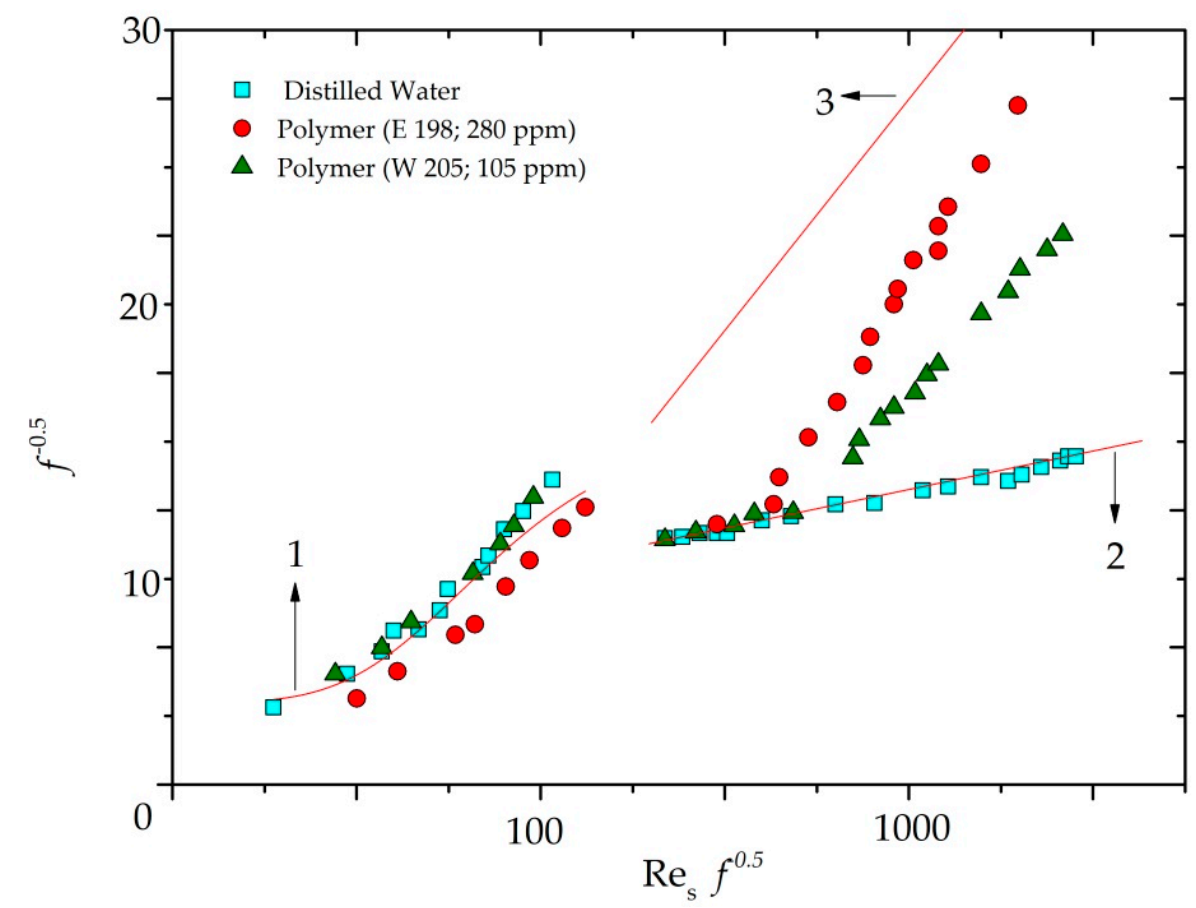

Figure 3. The resulting friction factor is based on two polymer species against three types of flow. 1: laminar flow, 2: Prandtl-von Kármán equation or turbulent flow, and 3: Virk's MDRA (maximum drag reduction asymptote).

Based on the flow in Figure 3, lines 1, 2, and 3 are linear lines as a reference when using polymers. The first line is a linear line based on Poiseuille's law when the Newtonian flow set in Equation (1) is laminar. The second line is a linear line influenced by the Prandtl-von Kármán law set in Equation (2). The third linear line is the slope difference based on Equations (9)-(11) by Virk's maximum drag reduction asymptote. In Virk's research, the effect of the concentration of several polymers was also discussed. The concentration affects the difference in the slope of the fluid, which in turn affects the friction factor and the resulting drag reduction. Based on the results of Figure 4 from Virk's research, the study does not reach a conclusion on which type of polymer is more efficient, but Virk provides a linear line as a reference for future research.

$$
\begin{gathered}
\delta(\text { slope })=S_{p}-S_{s} \\
S_{p}=\left[d\left(f^{-1 / 2}\right) / \operatorname{dlog}\left(\text { Re. } f^{1 / 2}\right)\right] ; \text { For polymer solution } \\
S_{s}=\left[d\left(f^{-1 / 2}\right) / \operatorname{dlog}\left(\text { Re. } f^{1 / 2}\right)\right] ; \text { For solvent }
\end{gathered}
$$




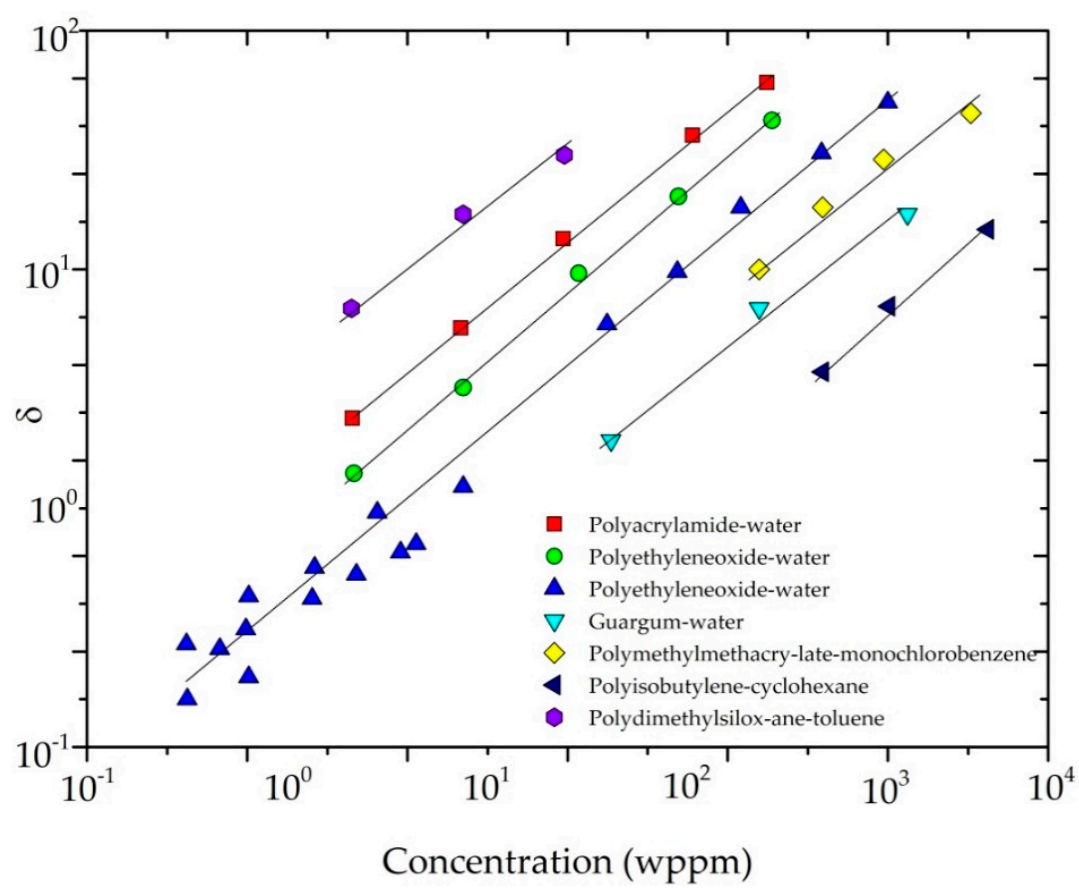

Figure 4. The concentration of polymer and solvent affects fluid slope; the slope then alters the drag reduction percentage.

\subsection{Solid Suspension Drag Reduction}

The solid suspension is based on the granular size of the smooth, straight, circular pipe, which is a good reference for the research carried out by Watanabe [115]. Experiments were carried out on several types of solid suspension, namely, carbon, $\mathrm{SiO}_{2}$, and kaolin in a laminar and turbulent flow. The research is supported by the equations formulated by Metzner [116], which are the same derivatives of Poiseuille's equation and the Kármán equation, which are distinguished based on the flow velocity. Based on research [115], the reduction in resistance can only be seen based on the flow characteristics, which are influenced by the rheological properties of the suspension used. The difficulty that is still being experienced is in determining the relationship between the differences in particle shape, given that the carbon suspension is black and difficult to study. If the liquid has a nanosized microstructure, the suspension will be transparent and easier to examine. Figure 5 shows the results of research on solid suspensions.

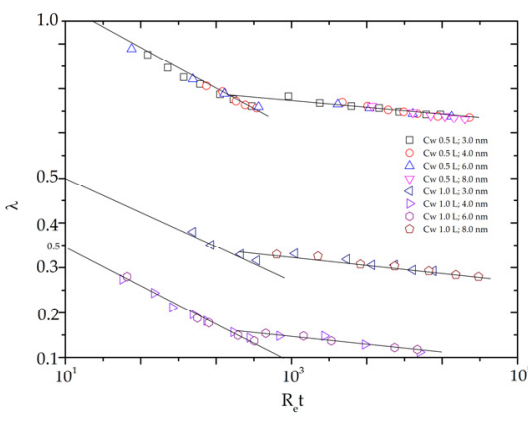

(a)

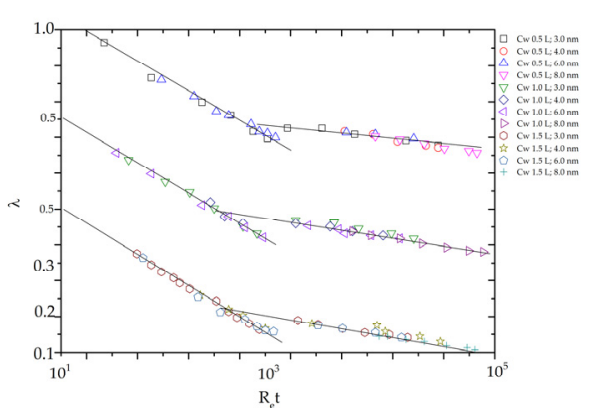

(b)

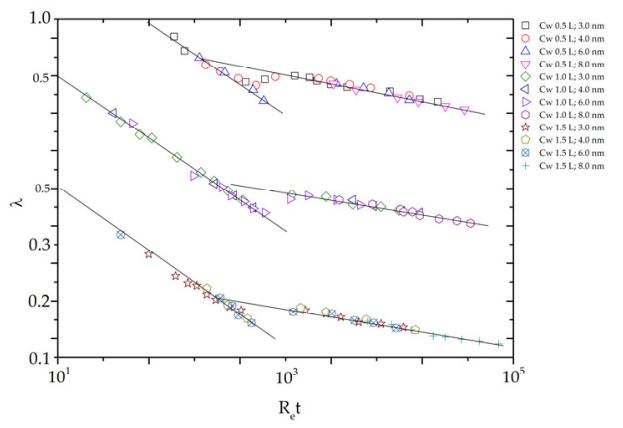

(c)

Figure 5. Comparison of friction factor to Reynold number of three kinds of solid suspension: (a) carbon; (b) $\mathrm{SiO}_{2}$; and (c) kaolin with different granular size. 


\subsection{Surfactant Drag Reduction}

Surfactants can be divided into two types, namely ionic and non-ionic surfactants. Among several sources, there are two good references in representing the results of experimental research on the use of surfactants. Representing studies on ionic surfactants, reference [117] researched two cationic surfactants, namely Ethoquad O/13 (oleyl tris(hydroxyethyl) ammonium acetate) and Ethoquad O/12 (oleyl bis(hydroxyethyl) methylammonium chloride). In the study, it was found that the drag reduction effect appears to decrease with the rising temperature surfactant, as can be seen in Figure 6. The addition of surfactants also causes the effect to reduce and destroys the previously formed micelles.

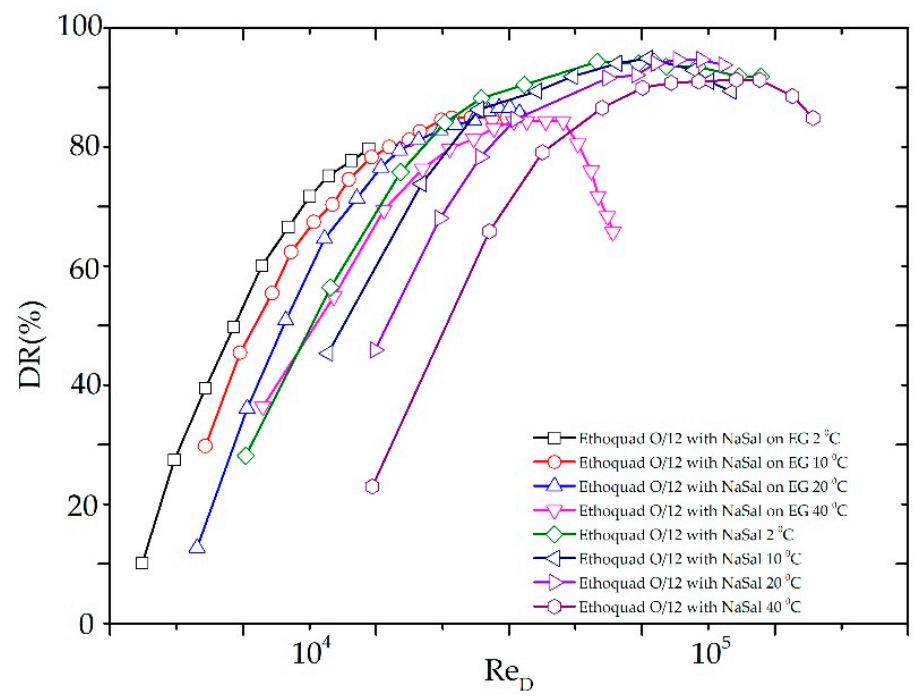

Figure 6. Drag reduction effect of Ethoquad O/12 with NaSal (sodium salicylate) in water and drag reduction effect of Ethoquad O/12 with NaSal on EG (ethylene glycol) with water at different temperatures.

Non-ionic surfactants have also been studied [118]. In one investigation, the addition of surfactants with the injection method was more effective than those mixed before experimenting. In this study, a comparison of PIV and LDV data collection results was also carried out. The differences found in the results comparing the tools were as follows. A significant function that can be distinguished is that PIV could record the direction of flow before and after the addition surfactants. This effect was seen when the flow was in turbulent flow by reducing turbulence from the interaction between the fluid layer and the pipe wall and reducing shear stress. Other studies that support the statement for the use of non-ionic surfactants include Cai et al. [119] on the use of oleyl di-methyl amine oxide (ODMAO), who found that when the concentration was at $400 \mathrm{ppm}$ and above, there was a drag reduction effect of 70 percent in straight pipes. The study also examined the effect of shear rate on different micelles resulting in different shear characteristics.

Meanwhile, with LDV only the effect on the shear stress of the wall could be observed. This finding is supported by the surfactant injection method [120,121]. The results of study [118] are shown in Figure 7. We can see the decrease of shear stress based on the length and the injection method using homogenous and non-homogenous surfactant injections; as a result, the drag is reduced within the range of $11-50 \%$. 


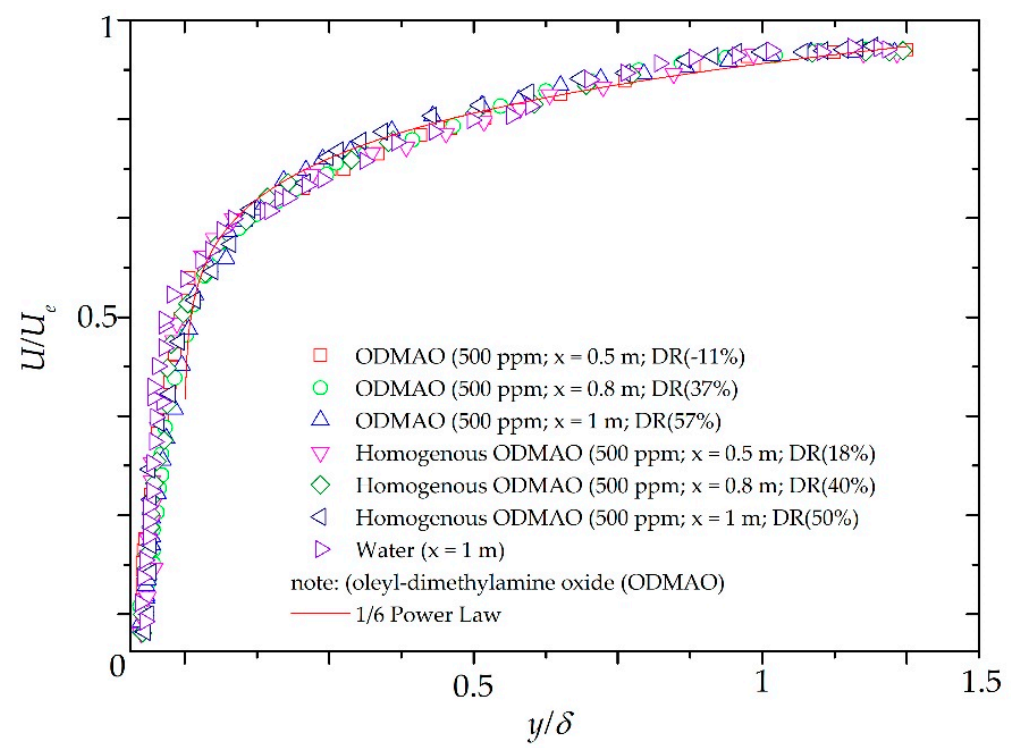

Figure 7. The comparison between homogenous and non-homogenous surfactant injection was affecting the drag reduction property.

\section{Conclusions}

The use of polymer-surfactant as a material for drag reduction is a technique that is low cost but also practical. This review cannot conclude which drag reducing agent would be more effective to use. However, we provide a more structured foundation on the topic, in contrast with some previous studies that do not distinguish between various additives. Based on the experiment results, it can be determined that the effect of the pipe diameter and the type of pipe used will always change along with the type, concentration, and flow velocity used. Research on polymers and surfactants in smooth pipes is more complex because many types of pipes should be discussed; however, this was outside the scope of this paper because of the Eddy effect due to the fluid rotation in the pipe. This modification will be discussed further in a following article, as the laws discussed above do not apply to the phenomenon in question. Materials regarding the use of surfactant polymers in straight, smooth, circular pipes can undoubtedly be developed by changing the composition of the flowing fluid, such as the use of microbubbles and the addition of granular compositions at different concentrations.

Following the above discussion, the concentration dramatically affects the drag reduction effect-the initial injection and mixing effect make the difference. Future developments that can be studied include if the effect is on time and how quickly it occurs because the chemical composition also changes with the duration of injection. Finally, in order to determine which, drag reduction is better, it is necessary to examine environmental effects. The ability to decompose is the main factor under consideration in this regard, in addition to the mechanical characteristics produced; this can be achieved by using a new, more eco-friendly material as a drag reduction agent.

Author Contributions: Conceptualization, Yanuar and A.U.; methodology, A.R.; validation, A.U., Gunawan, and A.R.; formal analysis, A.U.; investigation, A.U.; resources, Gunawan and A.R.; data curation, A.U.; writing-original draft preparation, A.U.; writing-review and editing, A.U. and Gunawan; visualization, A.U.; supervision, Yanuar; project administration, A.R.; funding acquisition, Yanuar. All authors have read and agreed to the published version of the manuscript.

Funding: This research was funded by the Ministry of Research and Technology/National Research and Innovation Agency of Indonesia, grant number NKB-041/UN2.RST/HKP.05.00/2021.

Conflicts of Interest: The authors declare no conflict of interest the funders had no role in the design of the study; in the collection, analyses, or interpretation of data; in the writing of the manuscript, or in the decision to publish the results. 


\section{References}

1. Forrest, F.; Grierson, G. Friction Losses in Cast Iron Pipe Carrying Paper Stock. Pap. Trade J. 1931, 92, 39-41.

2. Brautlecht, C.; Sethi, J. Flow of Paper Pulps in Pipe Lines. Ind. Eng. Chem. 1933, 25, 283-288. [CrossRef]

3. Brecht, W.; Heller, H. Der rohrreibungsverlust von stoffaufschwemmungen. Wochenbl. Für Pap. 1935, 16, 264, 342, 380, 439, 474, $529,587,641,714,747$.

4. Toms, B.A. Some observations on the flow of linear polymer solutions through straight tubes at large Reynolds numbers. Proc. Cong. Rheol. 1948, 2, 135-141. Available online: https://ci.nii.ac.jp/naid/10026798986/\#cit (accessed on 2 September 2021).

5. Oldroyd, J.G. A suggested method of detecting wall effects on turbulent flow through tubes. Proc. 1st Int. Congr. Rheol. N. Holl. Amst. 1948, 2, 130.

6. Weissenberg, K. A continuum theory of rhelogical phenomena. Nature 1947, 159, 310-311. [CrossRef]

7. Toms, B. Elastic and viscous properties of dilute solutions of poly(methyl)methacrylate in certain solvent/non-solvent mixtures. Rheol. Acta 1958, 1, 137-141. [CrossRef]

8. Shaver, R.G.; Merrill, E.W. Turbulent flow of pseudoplastic polymer solutions in straight cylindrical tubes. AICHE J. 1959, 5, 181-188. [CrossRef]

9. Metzner, A.B.; Park, M.G. Turbulent flow characteristics of visco-elastic fluids. J. Fluid Mech 1964, 20, 291-303. [CrossRef]

10. Ousterhout, R.S.; Hall, C.D. Reduction of friction loss in fracturing operations. J. Pet. Technol. 1969, 13, 217-222. [CrossRef]

11. Dever, C.D.; Harbour, R.J.; Siefert, W.F. Method of Decreasing Friction Loss in Flowing Liquids. U.S. Patent 3,023,760, 6 March 1962.

12. Warholic, M.D.; Schmidt, G.M.; Hanratty, T.J. The influence of a drag-reducing surfactant on a turbulent velocity field. J. Fluid Mech. 1999, 1, 388. [CrossRef]

13. Warholic, M.D.; Schmidt, G.M.; Hanratty, T.J. Influence of dragreducing polymers on turbulence: Effects of Reynolds number, concentration, and mixing. Exp. Fluids 1999, 27, 461. [CrossRef]

14. Fabula, A.G.; Hoyt, J.W.; Crawford, H.R. Turbulent flow characteristics of dilute aqueous solutions of high polymers. Bull. Am. Phys. Soc. 1963, 8, 15.

15. Hershey, H.C.; Zakin, J.L. Existence of two types of drag reduction in pipe flow of dilute polymer solutions. J. Ind. Eng. Chem. 1967, 6, 381-387. [CrossRef]

16. Fabula, A.G. The Toms Phenomenon in the turbulent flow of very dilute polymer solutions. In Proceedings of the 4th International Congress on Rheology, Pasadena, CA, USA, 3 August 1963.

17. Savins, J.G. Drag reduction characteristics of solutions of macromolecules in turbulent pipe flow. Soc. Petrol. Eng. J. 1964, 4, 203. [CrossRef]

18. Virk, P.S.; Merrill, E.W.; Mickley, H.S.; Smith, K.A. The Critical wall shear stress for reduction of turbulent drag in pipe flow. In Modern Developments in the Mechanics of Continua; Eskanazi, S., Ed.; Academic Press: New York, NY, USA, 1965.

19. Lumley, J.L. Drag reduction by additives. Annu. Rev. Fluid Mech. 1969, 1, 367-384. [CrossRef]

20. Patterson, G.K.; Zakin, J.L.; Rodriguez, J.M. Drag reduction: Polymer solutions, soap solutions, and solid particle suspensions in pipe flow. Ind. Eng. Chem. 1969, 61, 22-30. [CrossRef]

21. Hoyt, J.W. The effect of additives on fluid friction. Trans. ASME J. Basic Eng. 1972, 94, 258-285. [CrossRef]

22. Virk, P.S. Drag reduction fundamentals. AICHE J. 1975, 21, 625-656. [CrossRef]

23. White, A.; Hemmings, J.A.G. Drag Reduction by Additives: Review and Bibliography. BHRA Fluid Eng. 1976.

24. Shenoy, A.V. A review on drag reduction with special reference to micellar systems. Colloid Polym. Sci. 1984, $262,319-337$. [CrossRef]

25. Berman, N.S. Drag reduction by polymers. Annu. Rev. Fluid Mech. 1978, 10, 47-64. [CrossRef]

26. Hoyt, J.W.; Kroschwitz, J.; Mark, H.F.; Bikales, N.M.; Overberger, C.G.; Menges, G. Drag reduction. In Encyclopedia of Polymer Science and Engineering; Wiley-Interscience: New York, NY, USA, 1986; Volume 5, pp. 129-151. [CrossRef]

27. Zakin, J.L.; Lu, B.; Bewersdorff, H.W. Surfactant Drag Reduction. Rev. Chem. Eng. 1998, 14, 253-320. [CrossRef]

28. Nadolink, R.H.; Haigh, W.W. Bibliography on skin friction reduction with polymers and other boundary-layer additives. Appl. Mech. Rev. 1995, 48, 351-460. [CrossRef]

29. Manfield, P.D.; Lawrence, C.J.; Hewitt, G.F. Drag reduction with additives in multiphase flow: A literature survey. Multiph. Sci. Technol. 1999, 11, 197-221. [CrossRef]

30. Graham, M.D. Drag reduction in turbulent flow of polymer solutions. Rheol. Rev. 2004, 2, 143-170.

31. White, C.M.; Mungal, M.G. Mechanics and prediction of turbulent drag reducation with polymer additives. Annu. Rev. Fluid Mech. 2008, 40, 235-256. [CrossRef]

32. Al-Sarkhi, A. Effect of mixing on frictional loss reduction by drag reducing polymer in annular horizontal twophase flows. Int. J. Multiph. Flow 2012, 39, 186-192. [CrossRef]

33. Wang, Y.; Yu, B.; Zakin, J.; Shi, H. Review on Drag Reduction and Its Heat Transfer by Additives. Adv. Mech. Eng. 2011, 3, 478749. [CrossRef]

34. Abdulbari, H.A.; Shabirin, A.; Abdurrahman, H.N. Bio-polymers for improving liquid flow in pipelines-a review and future work opportunities. J. Ind. Eng. Chem. Jul. 2014, 20, 1157-1170. [CrossRef]

35. Nesyn, G.V.; Sunagatullin, R.Z.; Shibaev, V.P.; Malkin, A.Y. Drag reduction in transportation of hydrocarbon liquids: From fundamentals to engineering applications. J. Pet. Sci. Eng. 2017, 161, 715-725. [CrossRef] 
36. Xi, L. Turbulent drag reduction by polymer additives: Fundamentals and recent advances. Phys. Fluids 2019, 31, 1-37.

37. Soares, E.J. Review of mechanical degradation and de-aggregation of drag reducing polymers in turbulent flows. J. Nonnewton Fluid Mech 2020, 276, 104-225. [CrossRef]

38. Ayegba, P.; Edomwonyi-Otu, L.; Yusuf, N.; Abubakar, A. A Review of Drag Reduction by Additives in Curved Pipes for Single-Phase Liquid and Two-Phase Flows. Eng. Rep. 2020, 3, e12294. [CrossRef]

39. Broniarz-Press, L.; Rozanski, J.; Rozanska, S. Drag Reduction Effect in Pipe System and Liquid Failling Film Flow. Rev. Chem. Eng. 2007, 23, 149-245. [CrossRef]

40. Boffetta, G.; Celani, A.; Mazzino, A. Drag reduction in the turbulent Kolmogorov flow. Phys. Rev. E 2005, 71, 036307. [CrossRef]

41. Kim, C.; Choi, H.; Kim, C.; Jhon, M. Drag Reduction Characteristics of Polysaccharide Xanthan Gum. Macromol. Rapid Commun. 1998, 19, 419-422. [CrossRef]

42. Melton, L.L.; Malone, W.T. Fluid mechanics research and engineering applications in non-newtonian fluid systems. SPE J. 1974, 4, 56-66. [CrossRef]

43. Virk, P.S.; Mickley, H.S.; Smith, K.A. The ultimate asymptote and mean flow structure in Toms' phenomenon. J. Appl. Mech. 1970, 37, 488-493. [CrossRef]

44. Virk, P.S. An elastic sublayer model for drag reduction by dilute solutions of linear macromolecules. J. Fluid Mech. 1971, 45, 417-440. [CrossRef]

45. Hartley, G.S. Organised structure in soap solutions. Nature 1949, 163, 767-768. [CrossRef]

46. Gu, Y.; Yu, S.; Mou, J.; Wu, D.; Zheng, S. Research Progress on the Collaborative Drag Reduction Effect of Polymers and Surfactants. Materials 2020, 13, 444. [CrossRef]

47. Myska, J.; Simeckova, M. The shape of micelles of a complex soap causing the Toms effect. Colloid Polym. Sci. 1983, 261, 171-175. [CrossRef]

48. Savins, J.G. Contrasts in the solution drag reduction characteristics of polymer solutions and micellar systems. In Viscous Drag Reduction; Wells, C.S., Ed.; Springer: Boston, MA, USA, 1969; pp. 183-212.

49. Debye, P.; Anacker, E.W. Micelle shape from disymmetry measurements. J. Phys. Colloid Chem. 1951, 55, 644-655. [CrossRef]

50. Booij, H.L. Colloid Science II, Association Colloids, Ch. 14; Kruyt, H.R., Ed.; Elsevier Publishing Company: Amsterdam, The Netherlands, 1949; pp. 681-722. Available online: https:/ / www.scirp.org/(S(351jmbntvnsjt1aadkposzje))/reference/ReferencesPapers. aspx?ReferenceID=365552 (accessed on 2 September 2021).

51. Paterson, R.W.; Abernathy, F.H. Turbulent flow drag reduction and degradation with dilute polymer solutions. J. Fluid Mech. 1970, 43, 689-710. [CrossRef]

52. Gold, P.T.; Amar, P.K.; Swaidan, B.E. Friction reduction degradation in dilute poly (ethylene oxide) solutions. J. Appl. Polym. Sci. 1973, 17, 333-350. [CrossRef]

53. Sanders, J.V.; Henderson, B.H.; White, R. Effects of polyethylene oxide solutions on the performance of a small propeller. J. Hydronautics 1973, 7, 124-128. [CrossRef]

54. Little, R.C.; Patterson, R.L. Turbulent friction reduction by aqueous poly(ethylene oxide) polymer solutions as a function of salt concentration. J. Appl. Polym. Sci. 1974, 18, 1529-1539. [CrossRef]

55. Hoyt, J.W.; Fabula, A.G. The effect of additives on fluid friction. In Proceedings of the 5th Symposium on Naval Hydrodynamics, Bergen, Norway, 10-12 September 1964; Volume 112, p. 947.

56. Ramakrishnan, C.; Rodriguez, F. Drag reduction in nonaqueous liquids. AICHE Chem. Eng. Prog. Symp. Ser. 1973, 130, 52.

57. Rodriguez, J.M.; Zakin, J.L.; Patterson, G.K. Correlation of drag reduction with modified deborah number for dilute polymer solutions. SPE J. 1967, 7, 325-332. [CrossRef]

58. Ram, A.; Kadim, A. Shear degradation of polymer solutions. J. Appl. Polym. Sci. 1970, 14, 2145-2156. [CrossRef]

59. Polishchunk, A.M.; Raiskii, Y.D.; Temchin, A.Z. Effect of small addition of polyisobutylene on the turbulent flow of kerosene in a pipe. Neftyanoe Khozyaistvo Pet. Ind. 1972, 50, 60.

60. Martin, J.R.; Shapella, B.D. The effect of solvent solubility parameter on turbulent flow drag reduction in polyisobutylene solutions. Exp. Fluids 2003, 34, 535-539. [CrossRef]

61. Shanshool, J.; Al-Qamaje, H.M.T. Effect of molecular weight on turbulent drag reduction with polyisobutylene. NUCEJ Spat. 2008, 11, 52-59.

62. Farley, D. Drag Reduction in Nonaqueous Solutions: Structure-Property Correlations For Poly(Isodecyl Methacrylate). In Proceedings of the SPE Oilfield Chemistry Symposium, Dallas, TX, USA, 13-14 January 1975.

63. Holtmeyer, M.D.; Chatterji, J. Study of oil soluble polymers as drag reducers. Polym. Eng. Sci. 1980, 20, 473-477. [CrossRef]

64. Soares, E.; Silva, I.; Andrade, R.; Siqueira, R. The Role Played by The Flexible Polymer Polyacrylamide (PAM) and the Rigid Polymer Xanthan Gum (XG) On Drag In Taylor-Couette Geometry: From Taylor'S Vortexes To Fully Turbulent Flow. J. Braz. Soc. Mech. Sci. Eng. 2020, 42, 1-12. [CrossRef]

65. Nadolink, R.H. Friction reduction in dilute solutions of polystyrene (Technical Report 4422). Nav. Universea Syst. Cent. 1973, 1, 2233.

66. Kim, C.A.; Jo, D.S.; Choi, H.J.; Kim, C.B.; Jhon, M.S. A high-precision rotating disk apparatus for drag reduction characterization. Polym. Test. 2000, 20, 43-48. [CrossRef]

67. Ram, A.; Finkelstein, F.; Elata, C. Reduction of friction in oil pipelines by polymeradditives. Ind. Eng. Chem. Process. Des. Dev. 1967, 6, 309-313. [CrossRef] 
68. Yanuar; Gunawan; Baqi, M. The Effect of Guar Gum on Fluid Friction in Spiral Pipe. AIP Conf. Proc. 2012, 1440, $1313-1319$. Available online: https:/ / aip.scitation.org/doi/pdf/10.1063/1.4704353 (accessed on 2 September 2021).

69. Sohn, J. Drag-Reduction Effectiveness of Xanthan Gum in A Rotating Disk Apparatus. Carbohydr. Polym. 2001, 45, 61-68. [CrossRef]

70. Watanabe, K.; Ogata, S. Drag Reduction of Aqueous Suspensions of Fine Solid Matter in Pipe Flows. AIChE J. 2021, 67, e17241. [CrossRef]

71. Abubakar, A.; Al-Wahaibi, T.; Al-Wahaibi, Y.; Al-Hashmi, A.R.; Al-Ajmi, A. Roles of drag reducing polymers in single- and multi-phase flows. Chem. Eng Res. Des. Nov. 2014, 92, 2153-2181. [CrossRef]

72. Vanoni, V.A. Transportation of suspended sediment by water. Trans. ASCE 1946, 111, 67-133.

73. Vanasse, R.; Coupal, B.; Boulos, M.I. Hydraulic transport of peat moss suspensions. Can. J. Chem. Eng. 1979, 57, $238-241$. [CrossRef]

74. Yunqing, G.; Tao, L.; Jiegang, M.; Zhengzan, S.; Peijian, Z. Analysis of Drag Reduction Methods and Mechanisms of Turbulent. Appl. Bionics Biomech. 2017, 2017, 6858720. [CrossRef]

75. Vanoni, V.A.; Nomicos, G.N. Resistance properties of sediment laden streams. Trans. ASCE 1960, 125, 1140-1167.

76. Wang, Z.; Ren, S.; Huang, N. Saltation of Non-Spherical Sand Particles. PLoS ONE 2014, 9, e105208. [CrossRef] [PubMed]

77. Zandi, I. Decreased head losses in raw water conduits. J. Am. Water Work. Assoc. 1967, 59, 213-226. [CrossRef]

78. Loureiro, L.; Gil, P.; Vieira de Campos, F.; Nunes, L.; Ferreira, J. Dispersion and Flow Properties of Charcoal Oil Slurries (Chos) As Potential Renewable Industrial Liquid Fuels. J. Energy Inst. 2018, 91, 978-983. [CrossRef]

79. Mih, W.; Parker, J. Velocity profile measurements and a phenomenological description of turbulent fiber suspension pipe flow. TAPPI 1967, 50, 237-246.

80. Derakhshandeh, B.; Kerekes, R.; Hatzikiriakos, S.; Bennington, C. Rheology of Pulp Fibre Suspensions: A Critical Review. Chem. Eng. Sci. 2011, 66, 3460-3470. [CrossRef]

81. Bobkowicz, A.J.; Gauvin, W.H. Turbulent flow characteristics of model fiber suspension. Can. J. Chem. Eng. 1965, 43, 87-91. [CrossRef]

82. Gillissen, J.; Hoving, J. Self-Similar Drag Reduction in Plug-Flow of Suspensions of Macroscopic Fibers. Phys. Fluids 2012, 24, 111702. [CrossRef]

83. Peyser, P. The drag reduction of chrysotile asbestos dispersions. J. Appl. Polym. Sci. 1973, 17, 421-431. [CrossRef]

84. Moyls, A.; Sabersky, R. Heat Transfer and Friction Coefficients for Dilute Suspensions of Asbestos Fibers. Int. J. Heat Mass Transf. 1978, 21, 7-14. [CrossRef]

85. Savins, J.G. A stress controlled drag reduction phenomenon. Rheol. Acta 1967, 6, 323-330. [CrossRef]

86. Savins, J.G. Method of Decreasing Friction Loss in Turbulent Liquids. U.S. Patent 3,361,213, 2 January 1968.

87. Mysels, K.J. Early experiences with viscous drag reduction. In AIChE Chemical Engineering Progress Symposium Series III; 1971; Volume 67, pp. 45-49. Available online: https:/ /scholar.google.com/scholar?cluster=16083760666691089723\&hl=en\&as_sdt=20 05\&sciodt $=0,5$ (accessed on 2 September 2021).

88. Radin, I.; Zakin, J.L.; Patterson, G.K. Exploratory drag reduction studies in non-polar soap systems. In Viscous Drag Reduction; Wells, C.S., Ed.; Springer: Boston, MA, USA, 1969; pp. 213-231. [CrossRef]

89. Sheffer, H. Aluminum soaps as high polymers. Can. J. Res. 1948, 26, 481-498. [CrossRef]

90. Zakin, J.L.; Lee, K.C. Drag reduction in hydrocarbon-aluminum soap polymer systems. AICHE Chem. Eng. Prog. Symp. 1973, 130, 45. Available online: https://www.osti.gov/biblio/6069080 (accessed on 2 September 2021).

91. Dostál, M.; Šesták, J.; Mík, V.; Myška, J.; Toman, J.; Co, A.; Leal, G.; Colby, R.; Giacomin, A. Friction Factors for Flow of Drag Reducing Solutions of Micellar Surfactant Additives in Straight Circular Pipes and Conventional Globe Valves. AIP Conf. Proc. 2008, 1027, 132-134. [CrossRef]

92. Nash, T. Modification of the bulk mechanical properties of water by complex formation in dilute solution. Nature 1956, 177,948 . [CrossRef]

93. Nash, T. The interaction of some naphalene derivatives with a cationic soap below the critical micelle concentration. J. Colloid Sci. 1958, 13, 134-139. [CrossRef]

94. White, A. Studies of flow characteristics of dilute high polymer solutions. Henderson Coll. Technol. Res. Bull. 1968, 5, 113.

95. Zakin, J.L.; Poreh, M.; Brosh, A.; Warsharsky, M. Exploratory study of friction reduction in slurry flows. AICHE Chem. Eng. Prog. Symp. Ser. 1971, 67, 85-89.

96. Li, F.; Kawaguchi, Y.; Hishida, K. Structural analysis of turbulent transport in a heated drag-reducing channel flow with surfactant additives. Int. J. Heat Mass Transf. 2005, 48, 965-973. [CrossRef]

97. Li, F.; Kawaguchi, Y.; Hishida, K. Simultaneous measurements of velocity and temperature fluctuations in thermal boundary layer in a drag-reducing surfactant solution flow. Exp. Fluids 2004, 36, 131-140. [CrossRef]

98. Li, F.; Kawaguchi, Y.; Hishida, K. Investigation on the characteristics of turbulent transport for momentum and heat in a drag-reducing surfactant solution flow. Phys. Fluids 2004, 16, 3281-3295. [CrossRef]

99. Gasljevic, K.; Matthys, E.F.; Aguilar, G. On two distinct types of drag-reducing fluids, diameter scaling, and turbulent profiles. J. Non-Newton. Fluid Mech. 2001, 96, 405-425. [CrossRef]

100. Hellsten, M.; Harwigsson, I. Use of a Betaine Surfactant Together with an Anionic Surfactant as a Drag-Reducing Agent. WO Patent Application 96-EP950, 9628527, 11 May 1996. 
101. Hellsten, M.; Oskarsson, H. A Drag-Reducing Agent for Use in Injection Water at Oil Recovery. WO Application 2004/007630, 22 January 2004.

102. Zakin, J.L.; Chiang, J.L. Non-ionic surfactants as drag reducing additives. Nature 1972, 239, 26. Available online: https: / / data.epo.org/publication-server/document?iDocId=2898186\&iFormat=2 (accessed on 2 September 2021). [CrossRef]

103. Różański, J.; Różańska, S.; Mitkowski, P.T.; Szaferski, W.; Wagner, P.; Frankiewicz, A. Drag Reduction in the Flow of Aqueous Solutions of a Mixture of Cocamidopropyl Betaine and Cocamide DEA. Energies 2021, 14, 2683. [CrossRef]

104. Drzazga, M.; Gierczycki, A.; Dzido, G.; Lemanowicz, M. Influence of Nonionic Surfactant Addition on Drag Reduction of Water Based Nanofluid in A Small Diameter Pipe. Chin. J. Chem. Eng. 2013, 21, 104-108. [CrossRef]

105. Shenoy, A.V. Drag reduction with surfactants at elevated temperatures. Rheol. Acta 1976, 15, 658-664. [CrossRef]

106. Aguilar, G.; Gasljevic, K.; Matthys, E.F. Coupling between heat and momentum transfer mechanisms for drag-reducing polymer and surfactant solutions. ASME J. Heat Transf. 1999, 121, 796-802. [CrossRef]

107. Den Toonder, J.M.J.; Hulsen, M.A.; Kuiken, G.D.C.; Nieuwstadt, F.T.M. Drag reduction by polymer additives in a turbulent pipe flow: Numerical and laboratory experiments. J. Fluid Mech. 1997, 337, 193-231. [CrossRef]

108. Furuichi, N.; Terao, Y.; Wada, Y.; Tsuji, Y. Friction Factor and Mean Velocity Profile for Pipe Flow at High Reynolds Numbers. Phys. Fluids 2015, 27, 095108. [CrossRef]

109. Raffel, M.; Willert, C.; Scarano, F.; Kähler, C.; Wereley, S.; Kompenhans, J. PIV Uncertainty and Measurement Accuracy. Part. Image Velocim. 2018, 203-241.

110. Saga, T.; Hu, H.; Kobayashi, T.; Murata, S.; Okamoto, K.; Nishio, S. A Comparative Study of The PIV And LDV Measurements on A Self-Induced Sloshing Flow. J. Vis. 2000, 3, 145-156. [CrossRef]

111. McKeon, B.; Swanson, C.; Zagarola, M.; Donnelly, R.; Smits, A. Friction Factors for Smooth Pipe Flow. J. Fluid Mech. 2004, 511, 41-44. [CrossRef]

112. Swanson, C.; Julian, B.; Ihas, G.; Donnelly, R. Pipe Flow Measurements Over a Wide Range of Reynolds Numbers Using Liquid Helium and Various Gases. J. Fluid Mech. 2002, 461, 51-60. [CrossRef]

113. Österlund, J.; Johansson, A.; Nagib, H.; Hites, M. A Note on The Overlap Region in Turbulent Boundary Layers. Phys. Fluids 2000, 12, 1-4. [CrossRef]

114. Virk, P.; Baher, H. The Effect of Polymer Concentration on Drag Reduction. Chem. Eng. Sci. 1970, 25, 1183-1189. [CrossRef]

115. Watanabe, K. Drag Reduction in a Pseudo-Homogeneous Flow. In Drag Reduction of Complex Mixtures, 1st ed.; Guerin, B., Ed.; Academic Press: London, UK, 2018; Volume 4, pp. 83-84.

116. Metzner, A.B. Recent developments in the engineering aspects of rheology. Rheol. Acta 1958, 1, $205-212$.

117. Zhang, Y.; Schmidt, J.; Talmon, Y.; Zakin, J. Co-Solvent Effects on Drag Reduction, Rheological Properties and Micelle Microstructures of Cationic Surfactants. J. Colloid Interface Sci. 2005, 286, 696-709. [CrossRef]

118. Tamano, S.; Kitao, T.; Morinishi, Y. Turbulent Drag Reduction of Boundary Layer Flow with Non-Ionic Surfactant Injection. J. Fluid Mech. 2014, 749, 367-403. [CrossRef]

119. Cai, S.; Suzuki, H.; Komoda, Y. Drag-reduction of a nonionic surfactant aqueous solution and its rheological characteristics. Sci. China Technol. Sci 2012, 55, 772-778. [CrossRef]

120. Hou, Y.; Somandepalli, V.; Mungal, M. A Technique to Determine Total Shear Stress and Polymer Stress Profiles in Drag Reduced Boundary Layer Flows. Exp. Fluids 2006, 40, 589-600. [CrossRef]

121. Tamano, S.; Uchikawa, H.; Ito, J.; Morinishi, Y. Streamwise variations of turbulence statistics up to maximum drag reduction state in turbulent boundary layer flow due to surfactant injection. Phys. Fluids 2018, 30, 075103. [CrossRef] 